\title{
Online Counseling: A Narrative and Critical Review of the Literature
}

Richards, D., \& Viganó, N., Online Counseling: A Narrative and Critical Review of the Literature, Journal of Clinical Psychology, 69, 9, 2013, 994-1011

\begin{abstract}
Objective: This article aimed to critically review the literature on online counseling.

Method: Database and hand-searches were made using search terms and eligibility criteria, yielding a total of 123 studies.

Results: The review begins with what characterizes online counseling. Outcome and process research in online counseling is reviewed. Features and cyberbehaviors of online counseling such as anonymity and disinhibition, convenience, time-delay, the loss of social signaling, and writing behavior in cyberspace are discussed. Ethical behavior, professional training, client suitability, and clients' and therapists' attitudes and experiences of online counseling are reviewed.

Conclusion: A growing body of knowledge to date is positive in showing that online counseling can have a similar impact and is capable of replicating the facilitative conditions as face-to-face encounters. A need remains for stronger empirical evidence to establish efficacy and effectiveness and to understand better the unique mediating and facilitative variables.
\end{abstract}

The field of cyberpsychology involves the study of human experiences (cognitive, emotional, and behavioral) that are related to or effected by developing technologies, in other words the psychological study of human-technology interaction (Richards \& Viganó, 2012). One area of cyberpsychology is online counseling, also referred to as e-therapy, e-counseling, or cybertherapy. While the very nature and definition of online counseling have been debated, we will use the one employed by Richards and Viganó (2012), defining online counseling as the delivery of therapeutic interventions in cyberspace where the communication between a trained professional counselor and client(s) is facilitated using computer-mediated communication (CMC) technologies, provided as a stand-alone service or as an adjunct to other therapeutic interventions.

Alongside technological developments online counseling has grown in the past 15 or so years. Researchers in online counseling have been considering the potential effectiveness of online counseling and whether it is possible to establish a therapeutic relationship in cyberspace. Research studies have focused on establishing its potential benefits and challenges, client suitability for online 
counseling, therapists' and clients' attitudes and experiences of online counseling, and professional training for working online with clients.

Additionally, its very nature and definition as a therapeutic intervention has been debated. Researchers have been exploring newly observed phenomena that form part of understanding the psychology of online counseling behavior. Areas of interest include the effects of apparent anonymity and distance, disinhibition, identity and impression management, writing and emotional expression in cyberspace, and ethical behavior in cyberspace.

While other reviews of online counseling have been written, notably, the special issue from the Journal of Clinical Psychology, 2004, and the volume from The Counseling Psychologist, 2005, the contribution of the current article is the systematic nature of the work, and we believe the extensiveness and thoroughness of the work will provide the discipline with a comprehensive review of the field and also an evaluation of the present empirical knowledge and suggestions for the future clinical practice and research. The paper reviews, among others, research relating to process and outcome, the therapeutic relationship, the characteristic features of online counseling, and ethical considerations for delivering therapeutic interventions online.

\section{Method}

\section{Literature Search and Selection of Studies}

The aim of the literature search was to find all references related to online counseling. We drew on our research experience and knowledge of the field and we reached agreement regarding the means to carry out the search and the search terms to be used. A search of three leading databases for psychology (EMBASE, PubMed, and PsychINFO including PsychARTICLES) was conducted for studies published in peer-reviewed journals. Based on the literature, eight search terms were employed-online counseling and online counselling, cybercounseling and cybercounselling, web therapy, web counseling and web counselling, e-therapy, e-counseling and e-counselling, cybertherapy, and web consulting-culminating in a total of 24 searches.

Results, which included original research, meta-analysis, and other reviews, were assessed at title, abstract, or by reading the full paper to determine whether they met our eligibility criteria. Studies were included when they met (a) the definition of online counseling employed by Richards and Viganó (2012): involving the delivery of a therapeutic intervention by a trained professional to client(s) using synchronous or asynchronous computer mediated communication (CMC). Included were (b) papers that addressed any aspect of this encounter such as process and outcome studies, ethics, online behaviors associated with the encounter, training, suitability, its definition and nature, attitudes, experiences, (c) and all age groups. Papers were excluded (a) if they did not involve a trained professional counselor and client(s), (b) that did not deliver a therapeutic intervention e.g., careers guidance counseling or medical 
therapeutics, (c) and that did not use CMC, but instead telephone, or was solely a self-administered program.

We rejected duplicates and we assessed each of the studies for inclusion, any difficulties we discussed and a final decision was made. Further, a hand search was made of papers to identify other relevant studies for inclusion. Reasons for rejecting papers included that they were not a therapeutic intervention, were not in English, did not employ CMC, were an unpublished thesis, or a conference paper (see Figure 1). A comprehensive summary of information extracted from the papers was written, considering the characteristics of online counseling, associated process and outcome research, the therapeutic relationship in cyberspace, potential benefits and challenges, client suitability for online counseling, therapists' and clients' attitudes and experiences of online counseling, and professional training for working online with clients. Further, the review considered online behavior as it applies to online counseling: anonymity and distance, disinhibition, identity and impression management, writing and emotional expression, and ethical online behavior. 


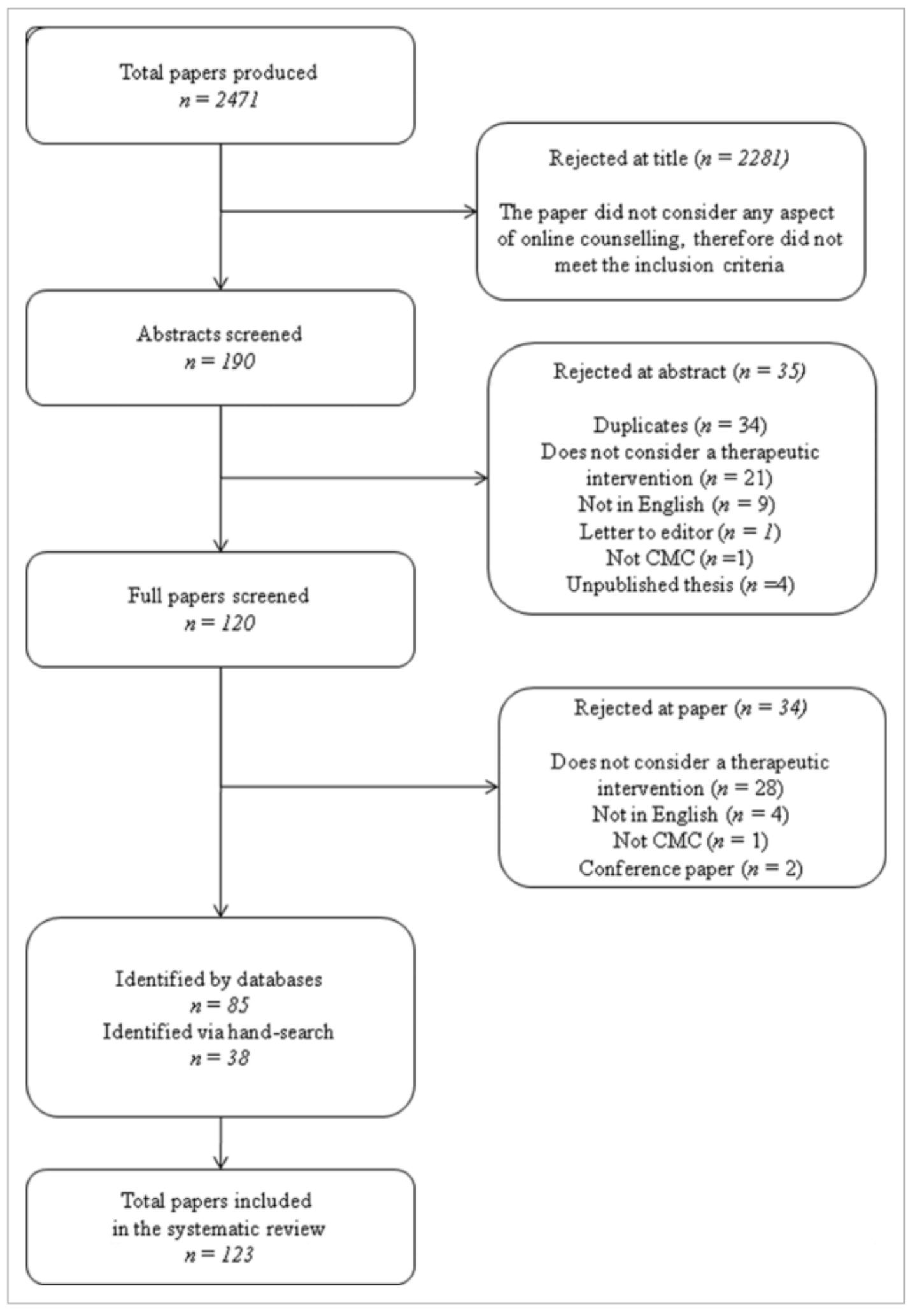

Figure 1.

Results from the systematic search. 
The subheadings under which the papers were reviewed evolved from the study of the papers and also from our own experience with online counseling. Therefore, some subheadings were initially derived as needing to be represented such as outcome and process research, the therapeutic relationship, benefits, and challenges, while others evolved more naturally from the literature and include attitudes, training, suitability, and unique features of online counseling behavior.

\section{Results and Discussion}

Three databases, PubMed ( $\mathrm{n}=1,163)$, EMBASE $(\mathrm{n}=1,124)$, and PsychINF0 including PsychARTICLES $(\mathrm{n}=185)$, were searched. Identified papers $(\mathrm{n}=$ 2,319) were screened against the established eligibility criteria, yielding 85 papers. A further 38 papers were identified through hand-search. Figure 1 shows the results of the systematic search.

\section{Characteristics of Online Counseling}

Providing a definition for online counseling is somewhat problematic as the exact nature of interventions involving therapists and clients online have been in flux and are a continued source of debate. Recently, Barak, Klein, and Proudfoot (2009) have tried to bring some clarity by providing some guiding definitions, classifications, and descriptions of a range of online therapeutic interventions. However, definitions still remain unspecific regarding any theoretical or technical approach, and professionals' level of training (Rochlen, Zack, \& Speyer, 2004).

Synchronous (chat and video conferencing) and more popularly asynchronous (e-mail) communication, as well as combinations of these have been employed to deliver online counseling as a standalone service and as an adjunct to other services. Some web-based, self-administered treatments for a variety of disorders have included online counseling support, usually in the form of asynchronous postsession feedback, which appears to increase adherence and yield enhanced outcomes (Newman, Szkodny, Llera, \& Przeworski, 2011; Richards \& Richardson, 2012).

Some (Castelnuovo, Gaggioli, Mantovani, \& Riva, 2003) consider that online counseling is a transposition of face-to-face (F:F) counseling online, with technologies mediating the therapeutic communication and affecting the process with their associated advantages and limitations. However, others (Fenichel et al., 2002; Grohol, 1999, 2001) consider that online counseling should be considered a new type of therapeutic intervention, a distinct way of engaging therapeutically and therefore needing a different theoretical framework from F:F counseling. From this perspective online counseling is considered a new, versatile, and flexible resource with the potential to complement and support other types of interventions.

A number of issues that have been debated in the literature from the beginning have been raised as criticisms by both professionals and laypeople (Barak, Hen, Boniel-Nissim, \& Shapira, 2008): the effect of the loss of cues on the process of therapy and consequently whether counseling can occur in such a context; ethical issues and in some cases their potential legal implications regarding the 
delivery of online counseling; and practical issues have arisen concerning training for conducting online counseling and concerns about relying on technology. Yet in spite of strong criticisms being put forward, from its beginning the various technology-delivered psychological interventions have flourished. Barak et al. (2009) state that this is likely due to several factors including:

- Increasing acceptability of the Internet as a legitimate social tool

- Computer hardware and software developments (especially in relation to ease of use, privacy protection, and online communication capabilities)

- Development of ethical guidelines by various professional organizations

- Growing research

- Establishment of online training for professionals

\section{Outcomes and Process Research in Online Counseling}

The goal of counseling is to alleviate the distress, anxiety, and concerns that clients can present. Counseling attempts to return a client to precrisis functioning and in doing so foster clients' well-being, build on a client's strengths, and help improve overall functioning (Mallen, Vogel, Rochlen, \& Day, 2005). It is our opinion that online counseling must also adhere to the same objectives, because it seems reasonable to assume that that is what users of counseling (online or F:F) are seeking.

Efficacy and effectiveness of online counseling

Cohen and Kerr's (1998) analogue study using the State-Trait Anxiety Inventory measured participants' anxiety before and after being assigned ( $\mathrm{N}=24$ students) to one session of either F:F or online synchronous (chat) counseling. Both groups showed a decrease in anxiety outcomes posttreatment. Although the study was somewhat artificial, as it used students to deliver and receive treatment, it screened out participants with high levels of distress, and the sample was small; nevertheless, it represented a worthwhile beginning.

The series of studies by Glueckauf and colleagues $(1999,2002)$ attempted to assess outcomes by randomizing teenagers $(\mathrm{N}=39)$ with epilepsy and their parents for six sessions of family counseling among video, audio, F:F counseling, and a waitlist control. They employed a number of measures such as the Problem Severity and Frequency Scale, Social Skills Rating System Scale, and a modified form of the Working Alliance Inventory, and they also tracked treatment adherence. Twenty-two families completed the treatment and data were collected at week 1 and 6 months posttreatment. They found that the teenagers and parents in each of the treatment groups demonstrated significant reductions in both problem severity and frequency at both posttreatment and 6-month follow-up. At posttreatment, prosocial behaviors increased, as reported by parents, and these were maintained at follow-up. However there didn't seem to be any changes in problem behaviors over time. The sample size was small and also the population very specific, thereby limiting generalizability of the results. 
Day and Schneider (2002) randomized 80 clients and compared process and outcome variables across three treatment groups: F:F, telephone, and video psychotherapy. Participants completed five sessions and measures of working alliance, session outcome, and satisfaction. The results showed no statistically significant differences between the three delivery modes for either working alliance or outcomes. However, they found a statistically significant difference in the level of participation: clients in distance therapy participated more actively than those in F:F therapy. The researchers speculated that the clients in the distance modes perhaps made more of an effort to communicate or took more responsibility for the interaction, or perhaps the distance made those participants feel safer. Although the study is an important contribution to empirically establish online counseling, it is limited by sample size and the broad range of presenting issues included (Day \& Schneider, 2002).

Robinson and Serfaty $(2001,2008)$ employed qualified therapists who corresponded with clients with an official Diagnostic and Statistical Manual of Mental Disorders (DSM-IV; American Psychiatric Association, 2000) diagnosis for an eating disorder via e-mail at least twice a week for a period of 3 months. The therapists were supervised by specialists with experience in eating disorders psychiatry, who received each e-mail correspondence, annotated it, and returned it to the therapist. Robinson and Serfaty (2001) reported significant improvements in bulimic symptoms for participants at 3-month follow-up and a significant reduction in the number of participants fulfilling DSM-IV eating disorder criteria at posttreatment (50\% of the 19 participants), compared with a waitlist control group. Although the samples were small and the design did not include a comparison with F:F treatment, the results are encouraging for the use of online counseling for eating disorders.

A number of studies employed videoconferencing technology to deliver therapy for the treatment of eating disorders. For instance Mitchell et al. (2008) delivered 20 sessions of cognitive-behavioral therapy (CBT) over a 16-week period for the treatment of bulimia nervosa (BN) in a sample of 128 adults meeting the DSM-IV criteria for BN or eating disorder not otherwise specified (EDNOS). Participants were randomly assigned to either F:F CBT or onlinedelivered CBT. Participants were assessed by interview at posttreatment, and at 3-month and 12-month follow-up. Retention was comparable in both groups, and abstinence rates were higher for the online group compared with the F:F group, but not statistically significant. They concluded that delivering online treatment was acceptable to many patients and roughly equivalent in outcome to F:F therapy.

Simpson and colleagues (Simpson, Bell, Knox, \& Mitchell, 2001; Simpson, Deans, $\&$ Brebner, 2005) have reported on the use of videoconferencing technology to deliver treatments for $\mathrm{BN}$ and eating disorders to remote and geographically distant populations. The first study (2001) assessed participants ( $=10) \mathrm{F}: \mathrm{F}$, and then assigned them to 10 sessions via teleconferencing. Prescores and postscores from the General Health Questionnaire (Goldberg, 1972) and postsession Clinical Outcomes in Routine Evaluation Outcome Measure (COREOM;Barkham et al., 2010) scores revealed that participants showed a decrease in symptamotology and increases in well-being. In a second study (2005) of six 
participants meeting DSM-IV criteria for BN or EDNOS, Simpson and colleagues reported finding that most participants made clinically important improvements in terms of bulimic symptoms, levels of depression, and borderline symptomatology. Although the studies included official diagnostic assessment of symptoms, they had small samples and lacked follow-up.

Zabinski and colleagues (Zabinski et al., 2001; Zabinski, Wilfley, Calfas, Winzelberg, \& Taylor, 2004) examined the use of synchronous Internetdelivered group chat for the prevention of eating disorders in four female students. The program was advertised as an educational intervention for women with elevated weight and shape concerns. It consisted of eight 1-hour weekly sessions. All sessions were moderated by an advanced graduate student in clinical psychology specializing in eating disorders. The study employed a number of standard self-report instruments, such as the Body Shape Questionnaire, Eating Disorders Inventory, and Eating Disorders Examination Questionnaire, and reported improvements ranging from small to medium effect sizes in eating disordered behavior and body image attitudes (Zabinski et al., 2001). A follow-up randomized controlled study demonstrated that intervention participants showed significant improvements over the waitlist control participants on most subscales of eating pathology with robust effect sizes, particularly from baseline to follow-up as measured by the Eating Disorder Examination Questionnaire (Zabinski et al., 2004).

Hopps, Pépin, and Boisvert (2003) employed chat technology to investigate the effect of cognitive-behavioral group therapy on feelings of loneliness among a sample $(\mathrm{N}=19)$ of chronically lonely people with physical disabilities. The study, using a waitlist control randomized design, employed a number of outcome assessments including the Loneliness Scale, Emotional Versus Social Loneliness Scale, and personal definitions of loneliness. The results showed significant improvements for participants on items regarding personal, social, and emotional loneliness and these were maintained at 4-month follow-up. Generalizing results is, however, limited by the sample size and the particular population studied.

Other online counseling interventions have been experimented with where users (adults and teenagers) have presented a broad variety of presenting concerns. At the University of Athens, students who used online asynchronous counseling noted advantages, including ease of use, speed, and anonymity, followed by ambivalence about traditional counseling (Efstathiou, 2009). The traditional social stigma toward seeking help and social factors hindering help-seeking behaviors (e.g., gender and physical appearance) appeared to be reduced (Efstathiou, 2009). Richards (2009), investigating asynchronous online counseling with students, highlighted the benefits for users in having one single session online with a counselor. Apparent anonymity and distance, the therapeutic benefits of writing, the cultivating of a zone of reflection, and the resourcefulness of young adult students were suggested to be important variables mediating the success of single-session online counseling. The singlesession model employed also allowed content to become a resource for all users (Efstathiou, 2009). The building of such a database is also supported by the work of Michaud and Colom (2003), where after 4 years of operation, the number of 
teenage visitors continued to increase but the number of questions dropped to half.

A meta-analysis of Internet-based psychotherapeutic interventions (Barak et al., 2008 ) reported an overall weighted mean pre-post effect size of $d=.53$. More precisely, the effects achieved for studies $(n=27)$ that represented work conducted synchronously $(\mathrm{d}=.49)$ and asynchronously $(\mathrm{d}=.44)$ were not statistically different, although chat and e-mail modes were statistically superior to forum, audio, or webcam. The study provides evidence for the use of online interventions, concluding that online interventions are as efficacious or nearly as efficacious as F:F ones. However, the study did not discriminate on the basis of quality, and was based on a wide variety of studies with mixed methods, approaches, and objectives.

Several randomized controlled trials that have included a treatment condition using synchronous or asynchronous online counseling have reported significant posttreatment and follow-up effects (Kessler et al., 2009; Vernmark et al., 2010), demonstrating the efficacy of delivering structured, online CBT treatments for depression (Richards \& Richardson, 2012). Similarly, a broad range of mental health issues have been addressed through the delivery of various online interventions, for instance, interventions for panic disorder (Carlbring et al., 2006; Carlbring, Ekselius, \& Andersson, 2003), insomnia (Ström, Pattersson, \& Andersson, 2004), and smoking cessation (Strecher, Shiffman, \& West, 2005), to name a few. Interventions included therapist support and counseling delivered through a range of technologies and communication modes, synchronously and asynchronously (Newman, et al., 2011).

Process variables in online counseling

The study by Cohen and Kerr (1998) described earlier reported that while clients rated higher levels of arousal in F:F encounters, there were no differences found regarding ratings of depth, smoothness, or positivity between online and F:F clients. Barak and Bloch (2006) using 140 transcripts investigated the perceived helpfulness of emotional support carried on by professional helpers through Internet chat with distressed individuals. They reported positive outcomes for clients who had used the service. They found no significant difference in clients' perceived session helpfulness for online than would be found with F:F services. Barak and Bloch (2006) have also demonstrated that perceived helpfulness correlated highly with impact from both clients' and therapists' perspectives. Similar to F:F therapy, deep, smooth conversations that yielded positive responses and aroused clients' emotions were helpful. This is in contrast with the common criticism that online therapeutic conversations might be shallow, superficial, or distant (Barak \& Bloch, 2006).

Their findings have also been confirmed by Reynolds, Stiles, and Grohol (2006), who studied session impact and alliance in online counseling with 16 therapists and 17 clients over the course of a total of 178 sessions and reported that session impact and alliance were similar between online and F:F treatments. This has also been a point noted in other studies, and perhaps session impact may be a variable more closely related to outcomes in online counseling than is 
the therapeutic alliance (King, Bambling, Reid, \& Thomas, 2006; Reynolds, Stiles, \& Grohol, 2006).

Liebert, Archer, Munson, and York (2006) using the Client Satisfaction Inventory (CSI; McMurtry \& Hudson, 2000) investigated satisfaction with online counseling, establishing a mean satisfaction rating of 67.8 (out of 100) for a sample of 81 participants. When benchmarked with F:F studies of satisfaction the authors concluded that clients were reporting satisfaction but less so than in F:F counseling (Liebert et al., 2006). For example, a validation study of the CSI in a F:F counseling sample generated a client satisfaction score of 88.1 (out of 100; McMurtry \& Hudson, 2000). The authors found that the more hours respondents spent online, the more likely they were to make use of online counseling. Noted advantages in using such a service included convenience, anonymity, and privacy. It can be speculated that some individuals presenting with specific issues, such as trauma, phobia, or social marginalization, may "need to communicate without fear of the listener's first reaction" (Liebert et al., 2006, p. 83).

In a more recent study the authors reported no statistically significant difference in satisfaction scores for F:F and online clients (Murphy et al., 2009). It would seem that satisfaction rating for online counseling have been high, yet perhaps not as high as those found in F:F studies, but, again, the studies were limited by small samples and there is only a small number of studies available.

Much valuable work has been achieved to investigate and establish an empirical base for online counseling. Yet the existing empirical literature that supports any in-session effects and the achievement of outcomes from online counseling, while positive, is limited at present. Consequently, apart from stating that it seems to work like it does in the F:F context, it is difficult to draw precise conclusions as to the efficacy and effectiveness of online counseling. Robust empirical investigations with larger samples and comparisons to F:F clients and/or control groups of some type would strengthen the empirical base. Additionally, investigating process variables that contribute to in-session events and eventual outcomes need further research, especially to find out whether they are the same predictors of outcomes as exist in F:F counseling.

\section{The Therapeutic Relationship in Online Counseling}

At the center of the therapeutic endeavor is the belief that a responsive relationship produces changes in cognition, feelings, and behaviors (Holmes \& Lisndley, 1989). In F:F counseling it has been noted that the early absence of the therapeutic alliance or the failure of it to develop is a likely indication that the therapy will be unsuccessful (Gelso \& Hayes, 1998). Research has demonstrated the importance of the working alliance to successful outcome in F:F counseling (Horvath \& Bedi, 2002; Martin, Garske, \& Davis, 2000). A significant challenge for online counseling is establishing the possibility to create equally meaningful relationships through $\mathrm{CMC}$.

The study described earlier by Glueckauf and colleagues $(1999,2002)$ used the Working Alliance Inventory (WAI) to compare the alliance in videoconferencing, audio phone, and F:F counseling for teenagers. While clients reported higher levels of alliance in the F:F condition, there did not exist any significant 
differences across the three treatment groups for the alliance. Another early study (Cohen \& Kerr, 1998) that compared the effects of computer-mediated online counseling and traditional F:F counseling on levels of anxiety and attitudes toward counseling reported that participants in both modes of delivery reported similar ratings regarding clients' perceptions of therapists' expertness, attractiveness, and trustworthiness.

Cook and Doyle (2002) in their study of 15 clients of online therapy-e-mail and chat-based-compared with a F:F sample $(\mathrm{N}=25)$, found equivalent alliance scores for both groups on the WAI. They reported significantly higher means on the goal subscale and the composite score for the WAI, suggesting that a working alliance as a central ingredient to outcome could also be established in online counseling. However, the study did not include a F:F comparison group and the self-selected sample were small. Qualitatively online clients reported experiencing strong bonds with their therapists and benefiting from the effects of disinhibition. This latter point perhaps supports McKenna and Bargh (2000) findings that individuals who are socially isolated and anxious and who have difficulties forming relationships are more likely to form deep and lasting relationships online than in person.

A review of the literature concluded that studies concerning the therapeutic alliance in online counseling were scarce, yielding mixed results (Mallen, Vogel, Rochlen, \& Day, 2005). However, the review (Mallen et al., 2005) considered only three studies regarding the therapeutic relationship in online counseling and, while they found that F:F contact was superior to online communication in establishing a relationship, no significant difference was found for emotional understanding. Since that literature review subsequent research seems to increasingly support the feasibility of developing therapeutic relationships online with modest to high alliance scores being consistently found.

For instance, Prado and Meyer (2004) in a study of the alliance in asynchronous online therapy reported that clients $(\mathrm{N}=53)$ and therapists $(\mathrm{N}=20)$ created solid working alliances as measured by the WAI. The study revealed significant differences in working alliance levels reported, greater for those who completed treatment $(n=29)$ compared with those who abandoned treatment early ( $n=$ 19). However, they concluded that it was possible to conduct therapy asynchronously online and the therapeutic relationship was similar to what is generally found in F:F studies.

Using a convenience sample of 81 participants Leibert, Archer, Munson, and York (2006) examined levels of therapeutic alliance in online counseling and compared them against levels found in F:F counseling. They showed that clients from F:F reported significantly higher ratings than those in online counseling; this was found to be the case on the composite and each of the three subscales of the WAI. Additionally, alliance scores significantly predicted respondent satisfaction with online counseling.

Reynolds, Stiles, and Grohol (2006) over a 3-year period recruited 30 clients for online counseling and examined session impact and alliance in online compared with F:F counseling and found that ratings of session impact, using the Session Evaluation Scale, and alliance, using the WAI, were similar between the two 
modes. Online therapists evaluated session impacts including depth, smoothness, and positivity alongside confidence aspects of the therapeutic alliance more highly than F:F therapists.

Hanley (2009) in a study of working alliance with young people $(\mathrm{N}=46)$ in online counseling reported that the majority (77\%) found the alliance to be of medium to high quality as rated by the Therapeutic Alliance Quality Scale. This research supports what King, Bambling, Reid, and Thomas (2006) found regarding the potential to create a working alliance of sufficient quality in online counseling that could have a positive impact on outcomes. The study investigated the alliance as measured by the Therapeutic Alliance Scale in a sample of young people $(\mathrm{N}=86)$ using a single session of online counseling.

This small collection of studies seems to demonstrate that alliance online appears to be capable of being equivalent to F:F. However, the fundamental question remains as to whether the same process variables that are strong predictors of success in F:F interventions play the same facilitative role in online interventions. King, Bambling, Reid, et al. (2006), for instance, found session impact to be a stronger mediator in online counseling than the working alliance. Given that these common factors of alliance and impact can be achieved online further research is welcome to investigate how these critical elements relate to outcome. One study of alliance quality and whether it could predict outcome (Knaevelsrud \& Maercker, 2006) found that although alliance in online treatment was one standard deviation higher than in F:F, there was only a low to modest association between alliance and outcome. They employed the short form of the WAI; their sample, however, was small $(\mathrm{N}=48)$ and all were being treated for trauma.

Although the research to date is largely positive, further research is needed to understand the nature and dynamics of online therapeutic relationships. Whether the therapeutic relationship is or is not a key facilitative element in online counseling still needs to be established. However, it would seem that for an interaction to have therapeutic value the basic principles of providing a supportive, empathic, and empowering relationship need to be present.

Features and Cyberbehaviors of Online Counseling

Online counseling is characterized by unique features and behaviors such as apparent anonymity, disinhibition, distance, time delay, convenience, and loss of social signaling. Such features and cyberbehaviors that characterize online counseling have associated benefits and challenges (Childress, 1998). For the most part these have been addressed adequately for the ethical and professional practice of online counseling through the provision of ethical and practice guidelines.

\section{Anonymity and disinhibition}

Traditionally, users of online counseling services enjoyed the apparent anonymity that the online environment provided, often using nicknames and not divulging many personal identifying details. However, this is becoming less the case; professional guidelines and ethical standards have brought about changes 
in how clients are recruited, identified, and assessed. This does not necessarily dissolve the potential of maintaining relative anonymity and especially geographical distance, which have been theorized to facilitate psychological safety, disinhibition, and increased self-disclosure (Suler, 2000, 2004). Disinhibition seems to aid clients to express themselves more openly and honestly (Cook \& Doyle, 2002); it is a powerful and distinct feature of online counseling and it is believed to have the potential to reduce the social stigma and anxieties that some experience in seeking professional support (Suler, 2004).

More sinister behaviors have the potential to arise from disinhibition, such as acting out behaviors with, for instance, the client engaging in identity and impression management (Suler, 2000). Although it is a point worth considering, it is not necessarily a behavior unique to online counseling, nor is there evidence to support its presence. Joinson (2001) examined the concept of self-disclosure by comparing dyads of undergraduate students interacting F:F and online. He found that instances of negative self-disclosure were rare and that participants in the CMC condition had significantly higher levels of self-disclosure, supporting the notion of positive disinhibition and demonstrating that acting out arising from disinhibition was uncommon.

\section{Convenience}

Both clients and therapists have identified convenience as a principal reason for choosing online counseling (Chester \& Glass, 2006; Mallen et al., 2005; Young, 2005). The accessibility of online counseling can overcome many barriers to accessing treatment including limited mobility due to geographical isolation or physical disability, language barriers, personal stigma in seeking help, or time availability (Rochlen, Zack et al., 2004). Online counseling, too, has the potential to extend access to specialized services that might otherwise be beyond the reach of clients (Young, 2005). One example is the use of videoconferencing to deliver specialized care and treatment to clients who were geographically isolated from specialist eating disorder treatment centers (Simpson et al., 2005).

Time delay

Using synchronous communication to provide online counseling can facilitate immediate clarification of what is being discussed between the therapist and the client. However, in asynchronous communication a time delay is built into the counseling process. This can potentially lead to anxieties for both therapists and clients in wondering about a perceived or unexplained delay in response. In turn, the ambiguity in the no-reply can become a blank screen where one can easily project one's own expectations, emotions, and anxieties, i.e., the "black hole phenomenon" (Suler, 2004).

At the same time, and unlike the urgency and immediacy characteristic of synchronous communication, asynchronous communication can facilitate the development of a zone of reflection where therapists and clients can take the time to reflect upon and respond to the others message (Suler, 2000). The process brings with it advantages for the client, principally a relief from any pressure of urgency or immediacy, and this in turn can facilitate time to process experiences and emotions; it can promote self-observation, increase awareness, 
reduce impulsivity, and enable clients to engage in deeper reflection and focus on self-expression (Hanley, 2009). Time delay is also a potential advantage for therapists as it can help with better observation and management of countertransference reactions.

\section{Loss of cues}

The fact that all of the visual and verbal cues that conveys subtle information about the person and their affect in F:F interactions are missing in text-based online counseling has been a point of debate in the literature (Suler, 2000). Suler (2004) argues that this feature is precisely a benefit in online counseling as it can lead to disinhibition. Disinhibition can occur as there is the potential to remove any concerns about the other person's reaction to one's narrative and presence. Feelings of psychological safety and disinhibition can arise from the lack of social signals, which in turn have the potential to reach clients who are particularly sensitive to the physical presence of another person and to cues indicating disapproval or judgment (Fenichel et al., 2002; Leibert, Archer, Munson, \& York, 2006). Leibert et al. (2006) concluded that the disinhibition effect reported by participants seemed to be stronger and offset the impact of the lack of cues.

Further derivates of the loss of cues include facilitating the disclosure of sensitive or embarrassing information. Clients can appreciate such an environment as it can increase their sense of control over what they disclose (Cohen \& Kerr, 1998; King, Bambling, Lloyd, et al., 2006; Simpson et al., 2005). A study by Hanley (2009) reported on young people's experience of online counseling and described how some users appreciated having the control over whether to disclose to their counselor that they were crying. However, a consideration needs to be that for some clients the experience of counseling that lacks the reassurance of regular social signaling may be distressing (Alleman, 2002).

Online counseling, in its many forms, brings with it features and newly observed behaviors. Some work has captured these phenomena, yet a more thorough investigation of these elements is worth considering, so as to, first, describe more thoroughly the phenomenon that is online counseling and, second, to contribute to the debate as to whether it is simply transferring what usually occurs in the F:F setting and now mediated by CMC or whether it is to be considered an entirely new and distinct intervention. Additionally, more needs to be explored about the therapeutic significance of different aspects (such as control over disclosure that ordinarily in face-to-face would be obvious such as crying) and unique features (disinhibition and time-delay) of online counseling.

Writing behavior and expression

The majority of online counseling has taken place through asynchronous textbased communication. Cook and Doyle (2002) reported that participants appreciated that they could re-read the responses received from the therapist, feeling this allowed them more time to process the content than verbal communication would have. Beattie, Shaw, Kaur, and Kessler (2009) in a study of online synchronous counseling with 24 primary care patients reported that on 
seeing their thoughts and emotions in writing online clients were effected and this also facilitated further self-reflection.

The positive benefit that writing can have on psychological and physical health has already been widely documented (Pennebaker, Kiecolt-Glaser, \& Glaser, 1988). The process of writing can, for instance, be cathartic in translating emotional experiences into words and this has also been found to be the case in the use of e-mail (Sheese, Brown, \& Graziano, 2004).

It is interesting to reflect that in writing the writer is in control of the content, the pace, and depth of the written material, which can potentially foster a sense of psychological safety (Wright \& Chung, 2001). Additionally, the permanency of the written record can be referred to again and again. The use of text as the means of communication, similar to narrative approaches to therapy and journal writing, can potentially facilitate the user's construction of a personal narrative (Suler, 2000). Indeed, writing may be a preferred or more suitable modality of self-expression for some individuals who are less comfortable in F:F interactions, while being unsuitable for individuals with limited writing skills (Suler, 2000).

Apart from any therapeutic intervention, the therapeutic benefit of writing in online counseling deserves more attention. It seems that writing can be of benefit to users of its own right. Additionally, practically nothing is known of counselors' experience of using writing to deliver interventions.

\section{Ethics}

Ethical concerns have been at the center of the debate regarding the practice of online counseling. Sampson, Kolodinsky, and Greeno (1997) identified ethical issues such as confidentiality, the validity of the data delivered via computer networks, the adequacy of counselor interventions, potential misuse of computer applications, a lack of awareness of location-specific factors, the effect of the digital divide, privacy concerns, credentialing, and issues that concerned the development of a therapeutic relationship. Many of the ethical concerns identified regarding the practice of online counseling also carry with them potential legal implications regarding duty of care (Shapiro \& Schulman, 1996).

Online counseling caused trepidation among professionals whom raised concerns regarding issues of informed consent, contracting, confidentiality of records, privacy, diagnosis, and duty of care (Bloom, 1998; Childress, 1998; Shapiro \& Schulman, 1996). However, Skinner and Zack (2004), for instance, maintain that the issues posed online are no more insurmountable than those faced in traditional practices. Nonetheless the concerns raised are legitimate and posed the question as to how was it going to be possible for professionals to practice ethically online?

In 1995, the American Psychology Association Ethics Board described the ethics code applicable to therapists using telephone, teleconferencing, and Internet services (Shapiro \& Schulman, 1996). The National Board for Certified Counselors (NBCC) developed standards for online practice (Bloom, 1998). These can be seen as early attempts to address ethical concerns and regulate the delivery of online counseling practice. 
In 1997 the International Society for Mental Health Online (ISMHO) was formed with a clear mission to promote the understanding, use, and development of online communication in mental health. They, too, have produced guiding principles for the ethical practice of online counseling (ISMHO, 2000). Indeed, many professional counseling and therapy accrediting bodies have followed suit and produced guidelines for online clinical practice that are regularly revised as the evidence-base from practice and research grows (Anthony \& Goss, 2009; Anthony \& Jamieson, 2005). The development of ethical frameworks has been significant in contributing to regulate and standardize the practice of online counseling.

However, despite the many developments that have occurred in recent years, a number of studies have surveyed online counseling websites (Chester \& Glass, 2006; Heinlen, Welfel, Richmond, \& Rak, 2003; Shaw \& Shaw, 2006) and reported that practitioner credentials varied widely, only $32 \%$ of practitioners requested that clients sign an informed consent form, and $42 \%$ of participants did not use any encryption to protect confidentiality, and they reported finding very low compliance with established ethical standards for online counseling. However, a high number of practitioners provided information about the limitations of online counseling.

In their study of 93 e-counselors attitudes, ethics, and practice, Finn and Barak (2010) reported that $62 \%$ of e-counselor practitioners were confident that their online sessions were confidential, $24 \%$ somewhat confident, and $14 \%$ not at all confident. They also described how only $28 \%$ of practitioners felt it important to confirm the identity of their users. Almost one fourth $(26 \%)$ had encountered a situation where a client was a danger to themselves or others. However, and worryingly, less than half (46\%) reported it to an appropriate authority (Finn \& Barak, 2010).

One can speculate that until online counseling is adopted and incorporated as a legitimate form of delivery of therapeutic interventions, thereby included in training courses for psychologists and as part of the broader field of psychology, regulated by appropriate and established accrediting bodies, it will continue to be considered by some as a renegade. Additionally, its incorporation would potentially ensure the industry is standardized and regulated and therefore more trustworthy for the consumer and other professionals.

\section{Attitudes and Experiences}

The literature on attitudes and experiences towards online counseling supports the view that users of online counseling and potential users seem to have been more accepting of online counseling than professionals (Mallen et al., 2005). One study that investigated psychologists $(\mathrm{N}=1040)$ attitudes towards delivering therapeutic interventions online found that the majority held a neutral attitude and only $3 \%$ viewed such delivery as unacceptable (Wangberg, Gammon, \& Spitznogle, 2007). However, the neutral attitudes found may suggest a lack of knowledge or simply a statement of not knowing or uncertainty. The study highlighted that those who frequently use the Internet or had experience using email in clinical practice were more favorable towards online counseling. Chester and Glass (2006) in a survey of the attitudes of 67 online counselors reported 
that $57 \%$ of respondents believed that online counseling was as effective as F:F counseling while $42 \%$ believed it was less effective.

Contracting, confidentiality, and informed consent have been some of the issues raised by professionals regarding their concerns about online counseling (Hanley, 2006). However, Hanley (2006) found that such concerns expressed by practitioners in developing an online counseling service for young people mirrored those that would be considered when establishing a F:F practice. Finn and Barak (2010) reported that the majority (74\%) of the e-counselors they surveyed were satisfied with their experience of their online counseling service.

At the same time therapists have also reported advantages about online counseling including that it can be of a lower emotional intensity, there is more time to think, the power balance seems more equal between the parties, and clients can be more focused and expressive (Bambling, King, Reid, \& Wegner, 2008). In relation to written and spoken records being kept verbatim, while potentially useful in supervision, they also increase the level of accountability for therapists (Murphy \& Mitchell, 1998). Certainly what seems evident is the level of ambivalence that therapists hold regarding delivering counseling online. One could speculate that it is largely because of a lack of exposure to online counseling and uncertainty, and a lack of knowledge regarding how it is operated and the benefits it can realize for users in particular.

Mallen et al. (2005) write how clients appear to have embraced online counseling with more ease than have professionals. However, an early study assessing attitudes towards online and F:F counseling noted that respondents had significantly more positive attitudes towards F:F than online counseling (Rochlen, Beretvas, \& Zack, 2004). However, the study sample comprised participants who had no experience with online counseling, and, therefore, the situation was presented as hypothetical. The study did show that unlike the traditional gender divide found in attitudes towards traditional counseling, there were no gender differences in attitudes towards online counseling, with an overall neutral to slightly positive attitude. The neutral result could be a similar response to the earlier study by Wangberg et al. (2007) regarding therapists attitudes, and could be referencing a lack of knowledge or uncertainty.

Anonymity, convenience, counselor credentials, access, and cost have been cited as primary reasons why someone would seek online counseling (Young, 2005). Qualitative studies have also identified the motivations for seeking online counseling; participants have reported their belief in the effectiveness of online counseling, and reported advantages included enhanced freedom of expression through writing, reduced costs, and convenience (Bambling et al., 2008; Beattie et al., 2009; Cook \& Doyle, 2002). On the contrary, concerns that users have about online counseling include the lack of privacy associated with the use of technology, the security of the technology being used, and being caught using online counseling (Young, 2005).

One thing that is unique is that attitudes and experiences toward online counseling seem to be effected by the level of comfort with the use of Internet technology (Leibert et al., 2006; Wangberg et al., 2007). As the pervasiveness of technology in people's lives grows, especially for younger generations, one can 
imagine that in the future seeking online counseling would not seem such a novelty but that there would be an expectation for counseling to be available online.

\section{Suitability}

The question as to who and what type of presenting issues are suitable to be dealt with through the medium of online counseling are still very much points of debate in the literature. Some practitioners advocate for this to be restricted to less serious issues (Haberstroh et al., 2008), some note specific advantages for specific populations and presentations (Simpson et al., 2005), while others advocate that the medium is adequate to address most issues at any level of severity (Fenichel et al., 2002). The lack of empirical research means that the opinions to date are largely anecdotal.

Very limited empirical research exists about the issues presented by online clients. Most services have dealt with a broad range of presenting issues, and some have targeted specific issues (Abroms, Gill, Windsor, \& Simons-Morton, 2009; Alemi et al., 2007; Mitchell et al., 2008; Robinson \& Serfaty, 2008; Simpson, 2009; Simpson et al., 2001; Zabinski et al., 2004). Apparently, however, there exists no difference between the presenting issues in online compared with F:F counseling (Leibert et al., 2006; Richards, 2009). Barak et al. (2008) reported that while all age groups showed benefits in online interventions individuals aged 19-39 years range appeared to benefit the most. Mostly, online counseling seems to attract female clients in the 20-40 years of age group which in fact mirrors the F:F counseling demographic (Chester \& Glass, 2006).

Finn and Barak (2010) reported that the majority of e-counselors (95\%) in their survey believed that e-counseling is appropriate for interpersonal and social issues and personal development. There was less agreement on issues that are considered a higher risk to a user's personal safety or well-being including suicidal thoughts, domestic violence, substance abuse, child abuse, and sexual assault.

It can, however, be stated that the use of the medium, as is true for other types of communication, may not suit everybody and that individual factors may be important in determining the success of online counseling (Fenichel et al., 2002). For instance, clients and therapists need to have a good ability for written expression and reading, as well as computer literacy (Fenichel et al., 2002; Rochlen, Zack, et al., 2004). Users, both therapists and clients, should also believe in the therapeutic benefits of online counseling (Fenichel et al., 2002).

Training

Finn and Barak (2010) reported that the majority of e-counselors (94\%) included in their survey reported that their professional training program did not include training in e-counseling. Instead, counselors learned about ecounseling through personal reading on the subject (92\%), informal consultation with colleagues (80\%), attending an e-counseling workshop (20\%), and attending an e-counseling training program (16\%). Their research concluded that the lack of consensus about ethical obligations and practice suggest the need 
for formal professional training in e-counseling and international cooperation in formulating practice ethics.

Training programs have been developed that offer certification in online counseling, to raise the awareness of ethical issues and promote the development of specialized skills for the effective provision of online counseling (Anthony \& Goss, 2003). Typically, participants are brought through a variety of theoretical and experiential modules, learning about the ethics of practice, establishing a relationship online, communicating effectively using CMC, and establishing an online practice. Alongside training courses several practitioner guidebooks and other written resources have been published (Grohol, 2003; Jones \& Stokes, 2009; Kraus, Striker, \& Zack, 2010; Maheu, Pulier, Wilhelm, \& McMenamin, 2004).

\section{Future Research}

The research to date has been largely positive in showing that online interventions can have a similar effect and are capable of replicating some of the facilitative conditions as F:F encounters. A need remains for stronger empirical evidence to establish efficacy and effectiveness and to provide a deeper understanding of the specific mediating and facilitative variables.

A particular area that appears to be underdeveloped in the literature concerns the role of the counselor: What now is the role of the counselor in the context of online counseling? Has it changed or is it changing, and if so how? Perhaps online counseling should be considered as a new type of intervention. A framework to define online counseling as a distinctive type of therapeutic intervention is therefore needed. Future theory and research would benefit from focusing on providing a clear theoretical framework for online counseling and on furthering our understanding of the suitability and adaptability of different therapeutic approaches for online delivery.

As a largely users' led development of the field, and with evidence suggesting that clients increasingly seek and adopt counseling online, the main duty of professionals is to ensure that there is an evidence base to guide best practice. A key aspect will be identifying the mechanisms that may be driving positive outcomes in online counseling. At present, we are dependent on the factors that drive change in F:F counseling, such as the therapeutic relationship, but as research develops it is likely that new factors will be identified, which may be responsible for change, for example, the distance between client and counselor may be an important factor that facilitates therapeutic change for some individuals.

\section{Conclusion}

What appears to emerge from reviewing the literature on online counseling to date is a picture of a growing body of knowledge forming a foundation for a more solid evidence base to be established. Urgency transpires in the literature in attempting to establish an evidence base to ensure safety in delivering therapeutic interventions online. The provision of ethical guidelines have provided for this need up to a point; however, alarming issues of noncompliance 
and lack of specialized training for professionals have been highlighted, and as the field develops, adherence to guidelines and the development of specialized skills would need to be pushed forward with professionals.

Increasing awareness among professionals in highlighting the distinct nature of online counseling, its defining features, dynamics, and issues to be considered in delivering online counseling would seem to be fundamental items to be put on the agenda for future clinical guidance. This could be achieved through the inclusion of training in online counseling in professional courses as well as part of continued professional development.

In spite of criticisms and skepticism coming from professionals more so than clients, there seems to have been a tacit acknowledgment that online counseling is an inevitable branching of the field, reflecting changes in how individuals relate and access services due to wider changes in society.

\section{References}

Abroms, L. C., Gill, J., Windsor, R., \& Simons-Morton, B. (2009). A process evaluation of e-mail counselling for smoking cessation in college students: Feasibility, acceptability and cost. Journal of Smoking Cessation, 4(1), 26-33.

Alemi, F., Haack, M. R., Nemes, S., Aughburns, R., Sinkule, J., \& Neuhauser, D. (2007). Therapeutic emails. Substance Abuse Treatment, Prevention, and Policy, 2. doi:10.1186/1747-597x-2-7

Alleman, J. R. (2002). Online counseling: The Internet and mental health treatment. Psychotherapy: Theory, Research, Practice, Training, 39(2), 199-209. doi:10.1037/0033-3204.39.2.199

American Psychiatric Association [APA]. (2000). Diagnostic and statistical manual of mental disorders (DSM$I V-T R$ ) (4th ed.). Washington D.C.: American Psychiatric Association.

Anthony, K., \& Goss, S. (2003). Conclusion. In S. Goss \& K. Anthony (Eds.), Technology in counselling and psychotherapy (pp. 195-208). London, UK: Palgrave.

Anthony, K., \& Goss, S. (2009). Guidelines for online counselling and psychotherapy 3rd edition, including guidelines for online supervision. Rugby, UK: BACP.

Anthony, K., \& Jamieson, A. (2005). Guidelines for online counselling and psychotherapy, 2nd edition, including guidelines for online supervision. Rugby, UK: BACP Publishing. 
Bambling, M., King, R., Reid, W., \& Wegner, K. (2008). Online counselling: The experience of counsellors providing synchronous single-session counselling to young people. Counselling \& Psychotherapy Research, 8(2), 110-116. doi:10.1080/14733140802055011

Barak, A., \& Bloch, N. (2006). Factors related to perceived helpfulness in supporting highly distressed individuals through an online support chat. CyberPsychology \& Behavior, 9, 60-68.

Barak, A., Hen, L., Boniel-Nissim, M., \& Shapira, N. (2008). A comprehensive review and a meta-analysis of the effectiveness of Internet-based psychotherapeutic interventions. Journal of Technology in Human Services, 26(2), 109-160. doi:10.1080/15228830802094429

Barak, A., Klein, B., \& Proudfoot, J. (2009). Defining Internet-supported therapeutic interventions. Annals of Behavioral Medicine, 38(1), 4-17. doi:10.1007/s12160-009-9130-7

Barkham, M., Mellor-Clark, J., Connell, J., Evans, C., Evans, R., \& Margison, F. (2010). Clinical Outcomes in Routine Evaluation (CORE) - The CORE measures and system: Measuring, monitoring and managing quality evaluation in the psychological therapies. In M. Barkham, G. E. Hardy \& J. Mellor-Clark (Eds.), Developing and delivering practice-based evidence: A guide for the psychological therapies. (pp. 175-219): Wiley Blackwell.

Beattie, A., Shaw, A., Kaur, S., \& Kessler, D. (2009). Primary-care patients' expectations and experiences of online cognitive behavioural therapy for depression: A qualitative study. Health Expectations: An International Journal of Public Participation in Health Care \& Health Policy, 12(1), 45-59. doi:10.1111/j.1369-7625.2008.00531.x

Bloom, J. W. (1998). The ethical practice of WebCounseling. British Journal of Guidance \& Counselling, 26(1), 53-59. doi:10.1080/03069889800760061

Carlbring, P., Bohman, S., Brunt, A., Buhrman, M., Westling, B. E., Ekselius, L., \& Andersson, G. (2006). Remote treatment of panic disorder: A randomized trail of Internet-based cognitive behaviour therapy supplemented with telephone calls. American Journal of Psychiatry, 163(12), 2119-2125.

Carlbring, P., Ekselius, L., \& Andersson, G. (2003). Treatment of panic disorder via the Internet: A randomised trial of CBT v's applied relaxation. Journal of Behaviour Therapy and Experimental Psychiatry, $34,129-140$.

Castelnuovo, G., Gaggioli, A., Mantovani, F., \& Riva, G. (2003). New and old tools in psychotherapy: The use of technology for the integration of the traditional clinical treatments. Psychotherapy: Theory, Research, Practice, Training, 40(1), 33-44. doi:10.1037/0033-3204.40.1-2.33

Cohen, G., \& Kerr, B. (1998). Computer-mediated counseling: An empirical study of a new mental health treatment. Computers in Human Services, 15, 13-26.

Cook, J. E., \& Doyle, C. (2002). Working alliance in online therapy as compared to face-to-face therapy: Preliminary results. CyberPsychology \& Behavior, 5(2), 95-105. doi:10.1089/109493102753770480

Chester, A., \& Glass, C. A. (2006). Online counselling: A descriptive analysis of therapy services on the Internet. British Journal of Guidance \& Counselling, 34(2), 145-160. doi:10.1080/03069880600583170

Childress, C. (1998). Potential risks and benefits of online psychotherapeutic interventions Retrieved from http://www.ismho.org/issues/9801.htm

Day, S. X., \& Schneider, P. L. (2002). Psychotherapy using distance technology: A comparison of face-toface, video and audio treatment. Journal of Counselling Psychology, 49(4), 499-503.

Efstathiou, G. (2009). Students' psychological web consulting: Function and outcome evaluation. British Journal of Guidance \& Counselling, 37(3), 243-255.

Fenichel, M., Suler, J., Barak, A., Zelvin, E., Jones, G., Munro, K., ... Walker-Schmucker, W. (2002). Myths and realities of online clinical work. CyberPsychology \& Behavior, 5(5), 481-497. doi:10.1089/109493102761022904

Finn, J., \& Barak, A. (2010). A descriptive study of e-counsellor attitudes, ethics, and practice. Counselling and Psychotherapy Research, 10(4), 268-277. doi:10.1080/14733140903380847

Gelso, C., \& Hayes, J. A. (1998). The psychotherapy relationship. New York, NY: John Wiley \& Sons.

Glueckauf, R. L., Fritz, S. P., Ecklund-Johnson, E. P., Liss, H. J., Dages, P., \& Carney, P. (2002). Videoconferencing-based family counseling for rural teenagers with epilepsy: Phase 1 findings. Rehabilitation Psychology, 47, 49-72.

Goldberg, D. (1972). The detection of psychiatric illness by questionnaire. Oxford: Oxford University Press.

Grohol, J. D. (1999). Best practices in eTherapy. Retrieved from http://psychcentral.com/best/best3.htm

Grohol, J. D. (2001). Best practices of eTherapy: Clarifying the definition of e-Therapy. Retrieved from www.psychcentral.com/best/best $5 / \mathrm{htm}$ 
Grohol, J. D. (2003). The Insider's Guide to Mental Health Resources Online. New York, NY: Guilford Publications, Inc.

Haberstroh, S., Parr, G., Bradley, L., Morgan-Fleming, B., \& Gee, R. (2008). Facilitating online counseling: Perspectives from counselors in training. Journal of Counseling \& Development, 86(4), 460-470.

Hanley, T. (2006). Developing youth-friendly online counselling services in the United Kingdom: A small scale investigation into the views of practitioners. Counselling \& Psychotherapy Research, 6(3), 182-185. doi: $10.1080 / 14733140600857535$

Hanley, T. (2009). The working alliance in online therapy with young people: Preliminary findings. British Journal of Guidance \& Counselling, 37(3), 257-269. doi:10.1080/03069880902956991

Heinlen, K. T., Welfel, E. R., Richmond, E. N., \& Rak, C. F. (2003). The scope of WebCounseling: A survey of services and compliance with NBCC Standards for the ethical practice of WebCounseling. Journal of Counseling \& Development, 81(1), 61-69.

Holmes, J., \& Lisndley, R. (1989). The values of psychotherapy. New York, NY: Oxford University Press.

Hopps, S. L., Pépin, M., \& Boisvert, J.-M. (2003). The effectiveness of cognitive-behavioral group therapy for loneliness via inter-relay-chat among people with physical disabilities. Psychotherapy: Theory, Research, Practice, Training, 40(1), 136-147. doi:10.1037/0033-3204.40.1-2.136

Horvath, A. O., \& Bedi, R. P. (2002). The alliance. In J. C. Norcross (Ed.), Psychotherapy relationships that work: Therapist contributions and responsiveness to patients. New York, NY: Oxford University Press.

International Society for Mental Health Online (ISMHO). (2000). Suggested principles for the online provision of mental health services Retrieved from https://www.ismho.org/suggestions.asp

Joinson, A. N. (2001). Self-disclosure in computer-mediated communication: The role of self-awareness and visual anonymity. European Journal of Social Psychology, 31(2), 177-192. doi:10.1002/ejsp.36

Jones, J., \& Stokes, A. (2009). Online counselling: A handbook for practitioners. London, UK: Palgrave Macmillian Ltd.

Kessler, D., Lewis, G., Kaur, S., Wiles, N., King, M., Weich, S., .. . Peters, T. J. (2009). Therapist-delivered Internet psychotherapy for depression in primary care: A randomised controlled trial. The Lancet, 374(9690), 628-634. doi:10.1016/S0140-6736(09)61257-5

King, R., Bambling, M., Lloyd, C., Gomurra, R., Smith, S., Reid, W., \& Wegner, K. (2006). Online counselling: The motives and experiences of young people who choose the Internet instead of face to face or telephone counselling. Counselling \& Psychotherapy Research, 6(3), 169-174. doi: $10.1080 / 14733140600848179$

King, R., Bambling, M., Reid, W., \& Thomas, L. (2006). Telephone and online counseling for young people: A naturalistic comparison of session outcome, session impact and therapeutic alliance. [Australian]. Counselling and Psychotherapy Research, 6(175-181).

Knaevelsrud, C., \& Maercker, A. (2006). Does the quality of the working alliance predict treatment outcome in online psychotherapy for traumatized patients. Journal of Medical Internet Treatment, 8(4).

Kraus, R., Striker, G., \& Zack, J. S. (2010). Online counselling: A handbook for mental health professionals. San Diego, CA: Elsevier.

Leibert, T., Archer, J., Munson, J., \& York, G. (2006). An exploratory study of client perceptions of Internet counseling and the therapeutic alliance. Journal of Mental Health Counseling, 28(1), 69-83.

Maheu, M., Pulier, M., Wilhelm, F., \& McMenamin, J. (2004). The mental health professional and the new technologies: A handbook for practice today. Hillsdale, NJ: Lawrence Erlbaum Associates.

Mallen, M. J., Vogel, D. L., Rochlen, A. B., \& Day, S. X. (2005). Online counseling: Reviewing the literature from a counseling psychology framework. The Counseling Psychologist, 33, 819-871.

Martin, D. J., Garske, J. P., \& Davis, M. K. (2000). Relation of the therapeutic alliance with outcome and other variables A meta-analytic review. Journal of Consulting and Clinical Psychology, 68(3), 438-450. doi:10.1037/0022-006X.68.3.438

McKenna, K. Y. A., \& Bargh, J. A. (2000). Plan 9 from cyberspace: The implications of the Internet for personality and social psychology. Personality and Social Psychology Review, 4(1), 57-75. doi:10.1207/s15327957pspr0401_6

McMurtry, S. L., \& Hudson, W. W. (2000). The Client Satisfaction Inventory: Results of an initial validation study. Research on Social Work Practice, 10(5), 644-663.

Michaud, P., \& Colom, P. (2003). Implementation and evaluation of an Internet health site for adolescents in Switzerland. The Journal of adolescent health: Official publication of the Society for Adolescent Medicine, 33(4), 287-290. 
Mitchell, J. E., Crosby, R. D., Wonderlich, S. A., Crow, S., Lancaster, K., Simonich, H., ... Myers, T. C. (2008). A randomized trial comparing the efficacy of cognitive-behavioral therapy for bulimia nervosa delivered via telemedicine versus face-to-face. Behaviour Research and Therapy, 46(5), 581592. doi:10.1016/j.brat.2008.02.004

Murphy, L. J., \& Mitchell, D. L. (1998). When writing helps to heal: E-mail as therapy. British Journal of Guidance \& Counselling, 26(1), 21-32. doi:10.1080/03069889800760031

Murphy, L. J., Parnass, P., Mitchell, D. L., Hallett, R., Cayley, P., \& Seagram, S. (2009). Client satisfaction and outcome comparisons of online and face-to-face counselling methods. doi:10.1093/bjsw/bcp041

Newman, M. G., Szkodny, L. E., Llera, S. J., \& Przeworski, A. (2011). A review of technology-assisted self-help and minimal contact therapies for anxiety and depression: Is human contact necessary for therapeutic efficacy? Clinical Psychology Review, 31(1), 89-103. doi:10.1016/j.cpr.2010.09.008

Pennebaker, J. W., Kiecolt-Glaser, J. K., \& Glaser, R. (1988). Disclosure of traumas and immune function: Health implications for psychotherapy. Journal of Consulting and Clinical Psychology, 56(2), 239-245.

Prado, S., \& Meyer, S. B. (2004). Evaluation of the working alliance of an asynchronous therapy via the Internet (unpublished master's thesis). University of Sao Paulo, Sao Paulo.

Reynolds, D. A. J., Jr., Stiles, W. B., \& Grohol, J. M. (2006). An investigation of session impact and alliance in Internet based psychotherapy: Preliminary results. Counselling \& Psychotherapy Research, 6(3), 164-168. doi: $10.1080 / 14733140600853617$

Richards, D. (2009). Features and benefits of online counselling: Trinity College online mental health community. British Journal of Guidance \& Counselling, 37(3), 231-242. doi:10.1080/03069880902956975

Richards, D., \& Richardson, T. (2012). Computer-based psychological treatments for depression: A systematic review and meta-analysis. Clinical Psychology Review, 32(4), 329-342. doi:10.1016/j.cpr.2012.02.004

Richards, D., \& Viganó, N. (2012). Online Counseling. In Y. Zheng (Ed.), Encyclopedia of Cyber Behavior (Vol. 1, pp. 699-713). New York, NY: IGI Global.

Robinson, P. H., \& Serfaty, M. A. (2001). The use of e-mail in the identification of bulimia nervosa and its treatment. European Eating Disorders Review, 9(3), 182-193. doi:10.1002/erv.411

Robinson, P. H., \& Serfaty, M. A. (2008). Getting better byte by byte: A pilot randomised controlled trial of email therapy for bulimia nervosa and binge eating disorder. European Eating Disorders Review, 16(2), 84-93. doi:10.1002/erv.818

Rochlen, A. B., Beretvas, S. N., \& Zack, J. S. (2004). The Online and Face-to-Face Counseling Attitudes Scales: A validation study. Measurement and Evaluation in Counseling and Development, 37(2), 95-111.

Rochlen, A. B., Zack, J. S., \& Speyer, C. (2004). Online therapy: Review of relevant definitions, debates, and current empirical support. Journal of Clinical Psychology, 60(3), 269-283. doi:10.1002/jclp. 10263

Sampson, J. P., Kolodinsky, R. W., \& Greeno, B. P. (1997). Counseling and the information highway: Future possibilities and potential problems. Journal of Counseling \& Development, 75(3), 203-212.

Shapiro, D. E., \& Schulman, C. E. (1996). Ethic and legal issues in e-mail therapy. Ethics \& Behavior, 6(2), 107-124. doi:10.1207/s15327019eb0602_3

Shaw, H. E., \& Shaw, S. F. (2006). Critical ethical issues in online counseling: Assessing current practices with an ethical intent checklist. Journal of Counseling \& Development, 84(1), 41-53.

Sheese, B. E., Brown, E. L., \& Graziano, W. G. (2004). Emotional expression in cyberspace: Searching for moderators of the Pennebaker disclosure effect via e-Mail. Health Psychology, 23(5), 457-464. doi:10.1037/0278-6133.23.5.457

Simpson, S. G. (2009). Psychotherapy via videoconferencing: A review. British Journal of Guidance \& Counselling, 37(3), 271-286.

Simpson, S. G., Bell, L., Knox, J., \& Mitchell, D. (2005). Therapy via videoconferencing: A route to client empowerment? Clinical Psychology \& Psychotherapy, 12(2), 156-165. doi:10.1002/cpp.436

Simpson, S. G., Deans, G., \& Brebner, E. (2001). The delivery of a tele-psychology service to Shetland. Clinical Psychology \& Psychotherapy, 8(2), 130-135. doi:10.1002/cpp.279

Skinner, A., \& Zack, J. S. (2004). Counseling and the Internet. American Behavioural Scientist, 48(4), $434-446$.

Strecher, V. J., Shiffman, S., \& West, R. (2005). Randomized controlled trial of a web-based computertailored smoking cessation program as a supplement to nicotine patch therapy. Addiction, 100(5), 682-688. doi:10.1111/j.1360-0443.2005.01093.x

Ström, L., Pattersson, R., \& Andersson, G. (2004). Internet-based treatment for insomnia: A controlled evaluation. Journal of Consulting and Clinical Psychology, 72, 113-120. 
Suler, J. (2000). Psychotherapy in Cyberspace: A 5-dimensional model of online and computer-mediated psychotherapy. CyberPsychology \& Behavior, 3(2), 151-159. doi:10.1089/109493100315996

Suler, J. (2004). The online disinhibition effect. CyberPsychology \& Behavior, 7(3), 321-326. doi:10.1089/1094931041291295

Vernmark, K., Lenndin, J., Bjärehed, J., Carlsson, M., Karlsson, J., Öberg, J., ... Andersson, G. (2010). Internet administered guided self-help versus individualized e-mail therapy: A randomized trial of two versions of CBT for major depression. Behaviour Research and Therapy, 48(5), 368-376. doi:10.1016/j.brat.2010.01.005

Wangberg, S. C., Gammon, D., \& Spitznogle, K. (2007). In the eyes of the beholder: Exploring psychologists' attitudes towards and use of e-therapy in Norway. CyberPsychology \& Behavior, 10(3), 418-423. doi: $10.1089 / \mathrm{cpb} .2006 .9937$

Wright, J., \& Chung, M. C. (2001). Mastery or mystery? Therapeutic writing: A review of the literature. British Journal of Guidance \& Counselling, 29(3), 277-291. doi:10.1080/03069880120073003

Young, K. S. (2005). An empirical examination of client attitudes towards online counseling. CyberPsychology \& Behavior, 8(2), 172-177. doi:10.1089/cpb.2005.8.172

Zabinski, M. F., Wilfley, D. E., Calfas, K. J., Winzelberg, A. J., \& Taylor, C. B. (2004). An interactive psychoeducational intervention for women at risk of developing an eating disorder. Journal of Consulting \& Clinical Psychology, 72, 914-919.

Zabinski, M. F., Wilfley, D. E., Pung, M. A., Winzelberg, A. J., Eldredge, K., \& Taylor, C. B. (2001). An interactive Internet-based intervention for women at risk of eating disorders: A pilot study. International Journal of Eating Disorders, 30(2), 129-137. doi:10.1002/eat.1065 